\title{
Contribuição ao conhecimento dos gêneros da tribo Ingeae ocorrentes em uma Floresta Nacional da Amazônia Brasileira ${ }^{1}$
}

Contribution to knowledge of Ingeae tribe genera from a Brazilian Amazon National Forest

\author{
Francismeire Bonadeu ${ }^{2,4}$ \& João Ubiratan Moreira dos Santos ${ }^{3}$
}

\begin{abstract}
Resumo
No trabalho apresenta-se tratamento taxonômico sobre as espécies dos gêneros Abarema Pittier, Calliandra Benth., Enterolobium Mart., Hydrochorea Barneby \& J. W. Grimes, Macrosamanea Britton \& Rose ex Britton \& Killip e Zygia P. Brawne que ocorrem na Floresta Nacional de Caxiuanã, acompanhado de chave taxonômica, descrições, ilustrações e comentários morfológicos e taxonômicos, além de dados de distribuição geográfica e períodos de floração e frutificação das espécies estudadas. Abarema foi o gênero com maior riqueza de espécies (3 spp.), seguido por Zygia (2 spp.), sendo os demais gêneros representados por uma espécie cada. As espécies A. auriculata (Benth.) Barneby \& J.W. Grimes, C. surinamensis Benth., H. corymbosa (Rich.) Barneby \& J.W. Grimes, M. pubiramea (Steud.) Barneby \& J.W. Grimes var. pubiramea e Z. latifolia var. lasiopus (Benth.) Barneby \& J.W. Grimes são novas ocorrências para a área de estudo.
\end{abstract}

Palavras-chave: Amazônia, Caxiuanã, Leguminosae, taxonomia.

\begin{abstract}
The study presents a taxonomic survey of Abarema Pittier, Calliandra Benth., Enterolobium Mart., Hydrochorea Barneby \& J. W. Grimes, Macrosamanea Britton \& Rose ex Britton \& Killip and Zygia P. Brawne species from the Caxiuanã National Forest, followed by an identification key, descriptions, illustrations, comments on morphology and taxonomy, geographic distribution and periods of flowering and fruiting. Abarema was the most representative genus ( $3 \mathrm{spp}$.) followed by Zygia (2 spp.). The remaining genera had one species each. The species A. auriculata (Benth.) Barneby \& J.W. Grimes, C. surinamensis Benth., $H$. corymbosa (Rich.) Barneby \& J.W. Grimes, M. pubiramea (Steud.) Barneby \& J.W. Grimes var. pubiramea and Z. latifolia var. lasiopus (Benth.) Barneby \& J.W. Grimes are new records in the study area.
\end{abstract}

Key words: Amazon, Caxiuanã, Leguminosae, taxonomy.

\section{Introdução}

A família Leguminosae Adans. possui cerca de 727 gêneros e 19.325 espécies, sendo considerada a terceira maior família de angiospermas e subdividida em três subfamílias: Caesalpinioideae, Mimosoideae e Papilionoideae (Lewis et al. 2005). Mimosoideae compreende quatro tribos (Acacieae Dumort., Ingeae Benth., Mimoseae Bronn e Mimozygantheae Burkart), 78 gêneros e aproximadamente 3.270 espécies (Lewis et al. 2005). Lewis \& Rico Arce (2005) reconheceram para a tribo Ingeae 36 gêneros, sendo 21 destes endêmicos do Novo Mundo, e 935 a 966 espécies.
Ingeae possui distribuição pantropical, ocorrendo nas regiões tropicais e subtropicais da América Central, América do Sul, África e Ásia-Austrália; no neotrópico, estende-se desde a América Central, distribuindo-se por toda a América do Sul (Pennington 1997). No Brasil, sua ocorrência é notada em todos os estados (Lima et al. 2010). Os gêneros de Ingeae somam 355 táxons para o Brasil, com 101 espécies, 17 variedades e quatro subespécies ocorrendo no estado do Pará (Garcia 2010; Garcia \& Fernandes 2010; Garcia et al. 2010; Iganci \& Morim 2010; Iganci 2010a-c; Lima 2010; Morim 2010a-e; Souza 2010; Souza

\footnotetext{
${ }^{1}$ Parte da dissertação de Mestrado apresentada ao Programa de Pós-Graduação em Botânica da Universidade Federal Rural da Amazônia/Museu Paraense Emílio Goeldi.

${ }^{2}$ Universidade Federal Rural da Amazônia/Museu Paraense Emílio Goeldi, Depto. Botânica, Av. Perimetral 1901, 66077-830, Belém, PA.

${ }^{3}$ Universidade Federal Rural da Amazônia, Inst. Ciências Agrárias-ICA, Av. Presidente Tancredo Neves 2501, 66077-530, Belém, PA.

${ }^{4}$ Autora para correspondência: francis_biologia@yahoo.com.br
} 
\& Lima 2010). Em Ingeae são reconhecidos dois grupos: um com folhas pinadas, representado pelo gênero Inga, outro com folhas bipinadas, constituído pelos demais gêneros (Romero 2005).

Segundo Luckow et al. (2003), Ingeae caracteriza-se por apresentar número indefinido de estames soldados na base. Elias (1981) considerou Mimoseae parafilética, a partir do qual Acacieae e Ingeae são derivadas. Estudos moleculares recentes (Luckow et al. 2000; Luckow et al. 2003) mostram que Ingeae, juntamente com Acaceae são grupos derivados de Mimoseae, porém Ingeae e Acaceae não estão bem sustentados, sendo necessárias mudanças no futuro em relação às circunscrições dos táxons desses dois grupos.

Nos trabalhos sobre Ingeae para as Américas, destacam-se os de Barneby \& Grimes (1996), que trataram os gêneros Abarema, Albizia e gêneros afins; Barneby \& Grimes (1997) trataram os gêneros Phitecellobium, Cojoba e Zygia e o de Barneby (1998), que tratou Calliandra.

Luckow et al. (2003) realizaram análise filogenética para Mimosoideae (analisando 17 dos 36 gêneros reconhecidos para a tribo Ingeae), e mostraram que apesar da subfamília ser monofilética, nenhuma das suas tradicionais tribos (com exceção de Mimozygantheae) são sustentadas como monofiléticas. Para Lewis et al. (2005), o esclarecimento das relações dos gêneros dentro da tribo Ingeae ainda sofre de escassez de dados moleculares, devido a falta de material apropriado para a extração de material genético dos gêneros descritos recentemente e reintegrados.

Na Floresta Nacional de Caxiuanã (Flona), o gênero Inga é até o momento, o melhor estudado para a área. No levantamento realizado por Almeida et al. (1993), o gênero foi representado por 20 espécies. Lisboa et al. (1997) listaram 14 espécies para o gênero na área, e mais recentemente, Bonadeu (2010) reconheceu 17 espécies de Inga para a Flona e apresentou um estudo taxonômico para as espécies. Para toda a tribo, Amaral et al. (2009) encontraram 11 espécies na área, no entanto, por se tratar de um estudo de espécies com potencial madeireiro, esse número foi provavelmente subestimado. A falta de estudos taxonômicos para os demais gêneros da tribo Ingeae motivaram o presente estudo. Assim sendo, aqui é apresentado um tratamento taxonômico dos demais gêneros da tribo, acompanhado de chave de identificação, descrições, ilustrações e comentários taxonômicos, além de dados sobre período de florescimento e frutificação e de distribuição geográfica das espécies.

\section{Material e Métodos}

O estudo foi realizado na Flona de Caxiuanã, área com aproximadamente $323.717,7$ ha., localizada na região noroeste do estado do Pará, a $400 \mathrm{~km}$ da capital. Os locais de coleta foram na grade do Programa de Pesquisa em Biodiversidade (PPBio), em uma área de $25 \mathrm{~km}^{2}$, dividida em 30 parcelas permanentes de $250 \times 40$ $\mathrm{m}$, georeferenciadas, no município de Portel e em Melgaço, na área de entorno da Estação Científica Ferreira Penna (ECFPn-MEPG) (Fig. 1).

O clima predominante na região é do tipo $A M_{i}$, segundo Köppen, caracterizado por um clima tropical úmido, com precipitação pluviométrica excessiva durante alguns meses, e de um a dois meses (outubro e novembro) com pluviosidade inferior a $60 \mathrm{~mm}$. O total anual de chuva fica entre 2.000 a $2.500 \mathrm{~mm}$; a temperatura média anual é em torno de $26^{\circ} \mathrm{C}$ e a umidade média relativa do ar é de $85 \%$ ao ano (Almeida et al. 1993). A cobertura vegetal da Flona é bastante diversificada, com ecossistemas típicos de florestas representados por áreas de terra firme e alagadas (igapó e várzea), além de manchas de vegetação secundária e vegetação não florestal, semelhantes a savanas (Lisboa \& Ferraz 1999).

A coleta do material botânico ocorreu de março a junho e de agosto a setembro de 2009, de acordo com as técnicas de Fidalgo \& Bononi (1984), através de escaladas com peconha, uso de podão e tesoura de poda para auxiliar na coleta do material. No sítio do PPBio coletou-se material a $20 \mathrm{~m}$ de cada lado da parcela. Na ECFPn-MPEG as coletas foram realizadas através de caminhadas ao longo da floresta (Filgueiras et al. 1994). Para as descrições das espécies, além do material coletado, contou-se também com o empréstimo de exsicatas das coleções dos herbários do Museu Paraense Emílio Goeldi (MG) e da Embrapa Amazônia Oriental (IAN).

A abreviatura dos nomes dos autores dos táxons está de acordo com Brummitt \& Powell (1992), os nomes e obras príncipes adotados seguiram Barneby \& Grimes (1996; 1997), Barneby (1998) e Tropicos (2010). Para as siglas dos herbários seguiu-se Holmgren et al. (1990).

A terminologia utilizada para as descrições das estruturas morfológicas seguiu Barneby \& Grimes (1996; 1997) e Barneby (1998), para 


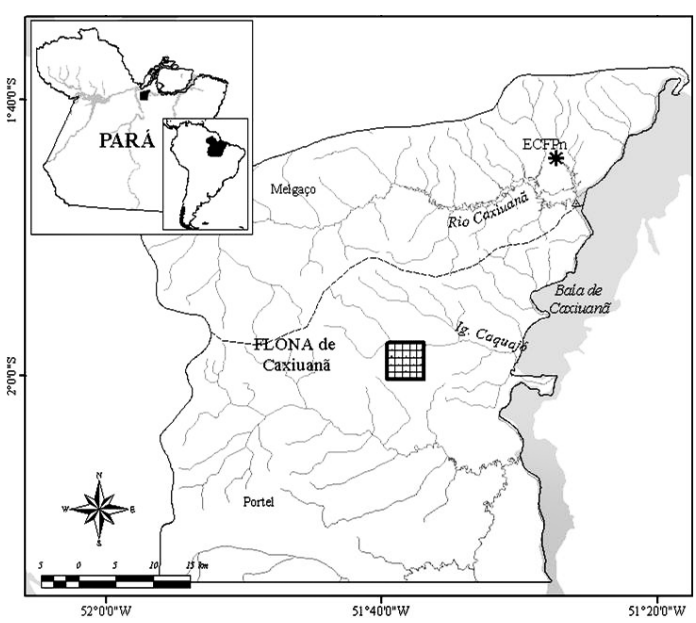

Figura 1 - Localização da área de estudo. Fonte: UAS/MPEG.

Figure 1 - Localion of study area. Source: UAS/MPEG.

hábito, ramos e caracteres da flor; Grimes (1999), para inflorescência; Garcia (1998), para nectários foliares; Gonçalves \& Lorenzi (2007), para venação, forma, ápice e base dos foliólulos e indumentos e Barroso et al. (1999), para fruto e sementes.
Os dados de distribuição geográfica, de floração e frutificação e ocorrência em diferentes formações vegetacionais foram obtidos das etiquetas dos exemplares examinados dos herbários MG e IAN, das observações em campo, da lista de espécies do Brasil (<http://www.floradobrasil.jbrj. gov.br/2010>) e das obras de revisões dos gêneros. A denominação das formações vegetacionais seguiu o conceito de Veloso et al. (1991).

\section{Resultados e Discussão}

Foram registradas nove espécies para a Flona de Caxiuanã distribuídas nos gêneros Abarema (com três espécies), Zygia (com duas espécies), Calliandra, Enterolobium, Hydrochorea e Macrosamanea (ambos com uma espécie cada). Destas, cinco espécies são novas ocorrências para a área de estudo (Abarema auriculata (Benth.) Barneby \& J.W. Grimes, Calliandra surinamensis (Benth.), Hydrochorea corymbosa (Rich.) Barneby \& J.W. Grimes, Macrosamanea pubiramea (Steud.) Barneby \& J.W. Grimes var. pubiramea e Zygia latifolia var. lasiopus (Benth.) Barneby \& J.W. Grimes).

\section{Chave para a identificação das espécies de Abarema, Calliandra, Enterolobium, Hydrochorea, Macrosamanea e Zygia na Flona de Caxiuanã}

1. Legumes.

2. Parafilídeo ausente; flores com dimorfismo.

3. Nectários extraflorais ausentes; flor central com disco intraestaminal presente.

4. Foliólulos elípticos, margem não ciliada, ápice atenuado; bractéolas espatuladas, tomentosas; flor periférica pedicelada, pedicelo com ca. $2 \mathrm{~mm}$ compr., cálice campanulado, não estriado, lobos obtusos; corola glabra, estriada

3. Abarema mataybifolia

4'. Foliólulos rômbicos ou rômbico-lanceolados, margem ciliada, ápice arredondado ou acuminado; bractéolas deltóides, pubescentes; flor periférica séssil, cálice tubular, estriado, lobos cuneados; corola pubescente, não estriada 4. Calliandra surinamensis

3'. Nectários extraflorais presentes; flor central com disco intraestaminal ausente.

5. Estípulas lineares, tomentosas a pubescentes; folhas com 5-7 pares de pinas; pecíolo e raque foliar não canaliculados; nectários extraflorais entre os foliólulos cupuliformes, estipitados; foliólulos, rômbico-elípticos ou rômbico-ovais; ovário glabro; frutos pedunculados, ápice arredondado, base cuneada 1. Abarema auriculata

5'. Estípulas lanceoladas, velutinas; folhas com 2-3 pares de pinas; pecíolo e raque foliar canaliculados, nectários extraflorais entre os foliólulos pateliformes, sésseis; foliólulos rômbicos; ovário densamente hirsuto; frutos sésseis, ápice acuminado ou cuneado, base aguda 2. Abarema jupunba var. jupunba

2'. Parafilídeo presente; flores sem dimorfismo.

6. Folhas com 2 pares de pinas; raque foliar ausente; foliólulos elípticos ou oval-elípticos, ápice acuminado ou levemente mucronado; bractéolas cimbiformes, pubescentes; flor com cálice estriado; ovário estipitado, tomentoso 8. Zygia latifolia var. laciopus 
6'. Folhas com 4-6 pares de pinas; raque foliar presente; foliólulos rômbico-lanceolados, ápice mucronado a mucronado-emarginado; bractéolas ovais, tomentosas; flor com cálice não estriado; ovário glabro, séssil 9. Zygia racemosa

1'. Legumes nucóides, lomentos drupáceos ou folículos

7. Foliólulos oblongos; frutos curvados; com faces lenhosas ......... 5. Enterolobium schomburkgii

7'. Foliólulos rômbico-lanceolados ou rômbico-ovais; frutos retos; com faces coriáceas ou cartáceas

8. Árvore; foliólulos com 4-7 pares, coriáceos, ápice obtuso; flores com dimorfismo; frutos com ápice apiculado, base atenuada

6. Hydrochorea corymbosa

8'. Arbusto; foliólulos com 9-20 pares, membranáceos, ápice cuneado, agudo ou arredondado; flores sem dimorfismo; frutos com ápice arredondado ou truncado, base cuneada

7. Macrosamanea pubiramea var. pubiramea

1. Abarema auriculata (Benth.) Barneby \& J. W. Grimes. Mem. New York Bot. Gard. 74(1): 62. 1996.

Fig. 2a-f

Árvore $10 \mathrm{~m}$ alt. Ramos velutinos. Estípulas 3-5 mm compr., lineares, tomentosas a pubescentes. Folhas 5-7 pares de pinas; pecíolo cilíndrico, não canaliculado, $1-0,5 \mathrm{~cm}$ compr., velutino; raque foliar cilíndrica, não canaliculada $1-10 \mathrm{~cm}$ compr., velutina; nectários extraflorais ausentes no pecíolo, presentes entre os folíolos, ca. $1 \mathrm{~mm}$ diâm., pateliformes, sésseis e entre os 1-2 pares de foliólulos terminais, ca. 0,5 mm diâm., cupuliformes, estipitados; foliólulos 5-13 pares, parafilídeo ausente, $0,8-2 \times 0,5-0,6 \mathrm{~cm}$, rômbico-elípticos ou rômbico-ovais, membranáceos, glabros em ambas as faces, nervura principal pubescente na face adaxial, margem ciliada, ápice arredondado ou cuneado, base aguda. Inflorescências capituliformes; pedúnculo 2,5-3,5 cm compr., pubescentes; raque floral ca. $2 \mathrm{~mm}$ compr.; bractéolas 2-3 mm compr., lineares ou lanceoladas, pubescentes. Flores com dimorfismo. Flor periférica com pedicelo, ca. 0,2 $\mathrm{mm}$ compr., cálice infundibuliforme, ca. $2 \mathrm{~mm}$ compr., pubescente, não estriado, lobos agudos, ca. $1 \mathrm{~mm}$ compr.; corola infundibuliforme, ca. $4 \mathrm{~mm}$ compr., pilosa, não estriada, lobos agudos, ca. $1 \mathrm{~mm}$ compr. Flor central séssil, cálice infundibuliforme, ca. $2 \mathrm{~mm}$ compr., pubescente, não estriado, lobos agudos, ca. $1 \mathrm{~mm}$ compr.; corola infundibuliforme, ca. $4 \mathrm{~mm}$ compr., pilosa a glabra, não estriada, lobos agudos, ca. $1 \mathrm{~mm}$ compr. Estames 1,5-2 cm compr., tubo estaminal incluso, filetes ca. 1 $\mathrm{mm}$ acima do tubo da corola, disco intraestaminal ausente; ovário estipitado, ca. $1 \mathrm{~mm}$ compr., glabro. Fruto do tipo legumes, com pedúnculo ca. $2 \mathrm{~mm}$ compr., $15 \times 2 \times 0,3 \mathrm{~cm}$, espiralados, glabros, ápice arredondado, base cuneada; faces coriáceas, convexas, reticuladas; margem ca. $3 \mathrm{~mm}$ esp. Sementes não vistas.
Material examinado: Melgaço, Caxiuanã, margem direita do Rio Curuá, 2.II.1991, fr., S. Almeida et al. 403 (MG). Material adicional: BRASIL. MANAUS: Itacoatiara, Colônia Santo Antônio, 8.IX.1966, fl., G.T. Prance et al. 2220 (MG). PARÁ: Porto Trombetas, fl. e fr., S.M. de Farria et al. 1042 (MG).

Segundo Iganci \& Morim (2010), a espécie é endêmica do domínio amazônico, ocorrendo nos estado do Pará, Amazonas e Acre. Na área de estudo a espécie foi coletada com frutos no mês de fevereiro em uma floresta aluvial (várzea), sendo um novo registro para a Flona de Caxiuanã.

Abarema auriculada apresenta estípulas lineares, tomentosas a pubescentes, folhas 5-7 pares de pinas, pecíolo e raque não canalicilados, nectários extraflorais entres os foliólulos cupuliformes, estipitados, foliólulos 5-13 pares, rômbico-elípticos ou rômbico-ovais, flores com cálice e corola infundibuliformes, ovário estipitado e glabro, frutos pedunculados, espiralados, ápice arredondado e base acuneada. Assemelha-se a $A$. jupunba var. jupunba (Willd.) Britton \& Killip pelos frutos espiralados, diferindo por apresentar pecíolo e raque foliar não canaliculados, de 5-13 pares de foliólulos, nectários extraflorais pedicelados entre os foliólulos, frutos pedunculados de ápice arredondado e base cuneada. Já $A$. jupunba var. jupunba possui o pecíolo e a raque foliar são canaliculados, com 4-7 pares de foliólulos, nectários extraflorais sésseis entre os foliólulos, frutos sésseis de ápice acuminado ou cuneado e base aguda. De acordo com Barneby \& Grimes (1996), as flores de A. auriculata apresentam diferença no tamanho, sendo a flor central séssil e maior que a flor periférica pedicelada, porém no presente estudo não foi observada diferença no tamanho das flores, mas a flor central apresentouse séssil e a periférica pedicelada como citado pelos autores. 


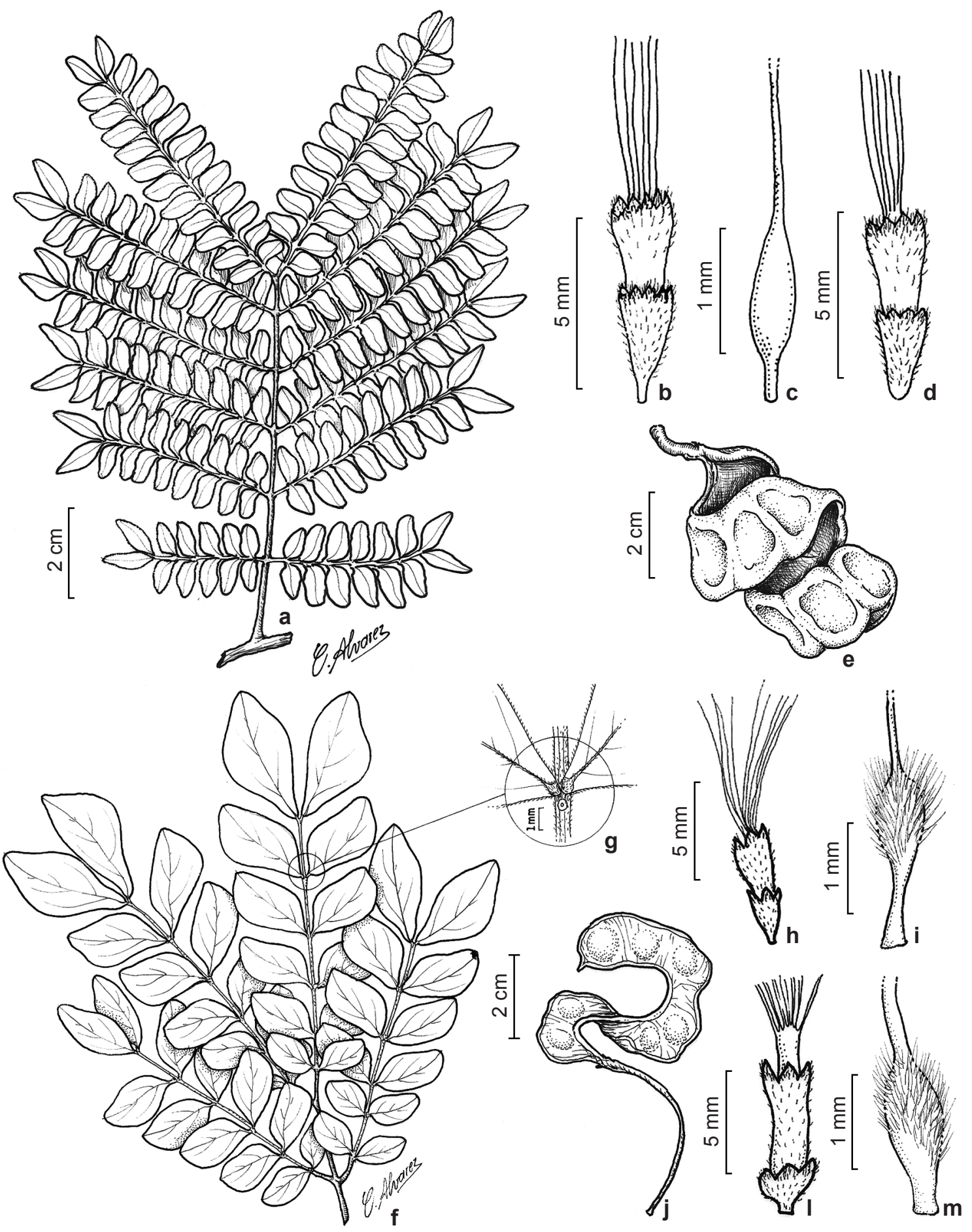

Figura 2 - Abarema auriculata: a. folha; b. nectário foliar; c. flor periférica; d. ovário; e. flor central; f. fruto (a-b, f S. Almeida 403; c-e G.T. Prance 2220). A. jupunba var. jupunba: g. folha; h. nectário foliar; i. flor periférica; j. ovário da flor periférica; 1. fruto; m. flor central; n. ovário da flor central (g-h, 1 A.S.L. da Silva \& M.C. da Silva 2414; i-j, m-n $M G$ 41840).

Figure 2 - Abarema auriculata: a. leaf; b. petiolar nectary; c. peripheral flower; d. ovary; e. central flower; f. fruit (a-b, f $S$. Almeida 403; c-e G.T. Prance 2220). A. jupunba var. japunba: g. leaf; h. petiolar nectary; i. peripheral flower; j. ovary of the peripheral flower; 1. fruit; m. central flower; n. ovary of the central flower (g-h, 1 A.S.L. da Silva \& M.C. da Silva 2414; i-j, m-n MG 41840). 
2. Abarema jupunba (Willd.) Britton \& Killip var. jupunba, Ann. New York Acad. Sci. 35(3): 126. 1936.

Fig. 2g-n

Árvore 4-8 m alt. Ramos velutinos a glabros. Estípulas 3-4 mm comp., lanceoladas, velutinas. Folhas com 2-3 pares de pinas; pecíolo canaliculado, 1,3-2 cm compr., velutino a pubescente; raque foliar canaliculada, 1,3-2,2 cm compr., pubescente; nectários extraflorais ausentes no pecíolo, presentes entre folíolos, 1-1,5 mm diâm., cupuliformes, sésseis e entre os foliólulos ca. $1 \mathrm{~mm}$ diâm., pateliforme, sésseis; foliólulos 4-7 pares, parafilídeo ausente, 0,9-3,7 × 0,6-2 cm, rômbicos, membranáceos, face abaxial pubescente, face adaxial glabra, nervura principal pubescente, margem ciliada, ápice arredondado, base aguda, assimétrica. Inflorescências capituliformes; pedúnculo 4,3-5,5 $\mathrm{cm}$ compr., pubescente; raque floral ca. $2 \mathrm{~mm}$ compr.; bractéolas ca. 1,25 mm compr., espatuladas, tomentosas. Flores com dimorfismo. Flor periférica com pedicelo, ca. $0,25 \mathrm{~mm}$ compr., cálice tubular, ca. $2 \mathrm{~mm}$ compr., tomentoso, não estriado, lobos agudos, ca. 0,25 mm compr.; corola tubular, ca. 4 $\mathrm{mm}$ compr., tomentosa, não estriada, lobos agudos, ca. $1 \mathrm{~mm}$ compr.; estames ca. 2,4 cm compr., tubo estaminal incluso ou exserto, filetes $1,5-2,2 \mathrm{~mm}$ acima da corola, disco intraestaminal ausente; ovário ca. $1 \mathrm{~mm}$ compr., estipitado, densamente hirsuto. Flor central séssil, cálice campanulado, ca. $2 \mathrm{~mm}$ compr., tomentoso, não estriado, lobos agudos, ca. $1 \mathrm{~mm}$ compr.; corola tubular, ca. $7 \mathrm{~mm}$ compr., tomentosa, não estriada, lobos agudos, ca. $1,25 \mathrm{~mm}$ compr.; estames ca. $1,8 \mathrm{~cm}$ compr., tubo estaminal exserto, filetes $5-8 \mathrm{~mm}$ acima da corola, disco intraestaminal ausente; ovário séssil, ca. 1,5 $\mathrm{mm}$ compr., densamente hirsuto. Frutos do tipo legumes, sésseis, 8,8-9,4×1×0,2 cm, espiralados, pilosos, ápice acuminado ou cuneado, base aguda; faces coriáceas, convexas, não reticuladas; margem ca. $1 \mathrm{~mm}$ esp. Sementes 8-10, ovóides, $7 \times 5-6 \mathrm{~mm}$. Material examinado: Melgaço, Caxiuanã próximo ao Igarapé Puraquequara, 15.X.1991, fl., A.S.L. da Silva \& M.C. da Silva 2.414 (MG).

Material adicional: BRASIL. PARÁ: Santa Isabel, Região Bragantina, 1970, fr. (MG 41840).

No Brasil ocorre nos estados do Pará, Amazonas, Acre, Ceará, Paraíba, Pernambuco, Bahia, Alagoas, Sergipe e Espírito Santo (Iganci $\&$ Morim 2010). No presente estudo a espécie foi coletada com flores no mês de outubro em uma floresta ombrófila densa no município de Melgaço. Segundo Iganci (2008), a espécie floresce de junho a fevereiro e frutifica de fevereiro a outubro.
Abarema jupunba var. jupunba é reconhecida por suas estípulas lanceoladas, velutinas, folhas 2-3 pares de pinas, pecíolo e raque canaliculados, nectários extraflorais entre os foliólulos pateliformes, sésseis, foliólulos 4-7 pares, rômbicos de margem ciliada, ovário densamente hirsuto, frutos do tipo legumes, sésseis, espiralados, ápice acuminado ou cuneado, base aguda e sementes ovóides. No estudo realizado por Barneby \& Grimes (1996), A. jupunba var. jupunba apresentou ovário densamente pubescente, o que está em desacordo com a espécie aqui estudada, pois apresenta o ovário densamente hirsuto.

Abarema jupunba apresenta duas variedades, A. jupunba var. jupunba caracterizada por apresentar foliólulos entre $(1,3-) 1,6-3,5(3,6) \times$ $1,0-1,9(-2,1) \mathrm{cm}$ e com distribuição disjunta para o Brasil (entre a Amazônia e o litoral), já A. jupunba var. trapezifolia (Vahl) Barneby \& J.W. Grimes apresenta foliólulos entre $(3,4-) 3,5-6,5(-7,0) \times$ 1,9-3,6 cm, com distribuição restrita a Amazônia (Barneby \& Grimes 1996). A espécie aqui estudada foi classificada como A. jupunba var. jupunba por apresentar as dimensões dos foliólulos $(0,9-3,7 \times$ 0,6-2 cm) mais próximo no observado por Barneby \& Grimes (1996) para a variedade citada.

3. Abarema mataybifolia (Sandwith) Barneby \& J. W. Grimes, Mem. New York Bot. Gard. 74(1): 78. 1996.

Fig. 3a-e

Árvore 7-23 m alt. Ramos pilosos a glabros. Estípulas não visualizadas. Folhas com 1-2 pares de pinas; pecíolo cilíndrico, não canaliculado, 1,1-3,2 cm compr., glabro; raque foliar ausente; nectários extraflorais ausentes no pecíolo e entre folíolos e foliólulos; foliólulos 2-3 pares, parafilídeo ausente, 4,6-11,1 × 2,1-4,4 cm, elípticos, membranáceos, glabros, margem não ciliada, ápice atenuado, base atenuada. Inflorescências capituliformes; pedúnculo 2-4,6 cm compr., pubescente; raque floral ca. $3 \mathrm{~mm}$ compr.; bractéolas ca. 1,5 $\mathrm{mm}$ compr., espatuladas, tomentosas. Flores com dimorfismo. Flor periférica com pedicelo ca. 2 mm compr., cálice campanulado, 1-1,25 mm compr., pubescente, não estriado, lobos obtusos, ca. $1 \mathrm{~mm}$ compr., pubescentes; corola tubular, ca. $3 \mathrm{~mm}$ compr., glabra, estriada, lobos agudos, ca. $2 \mathrm{~mm}$ compr., pubescentes; estames ca. 2,5 cm compr., tubo estaminal exserto, filetes ca. $2 \mathrm{~cm}$ acima da corola, disco intraestaminal ausente. Flor central séssil, cálice campanulado, ca. $2 \mathrm{~mm}$ compr., pubescente, não estriado, lobos obtusos, ca. 


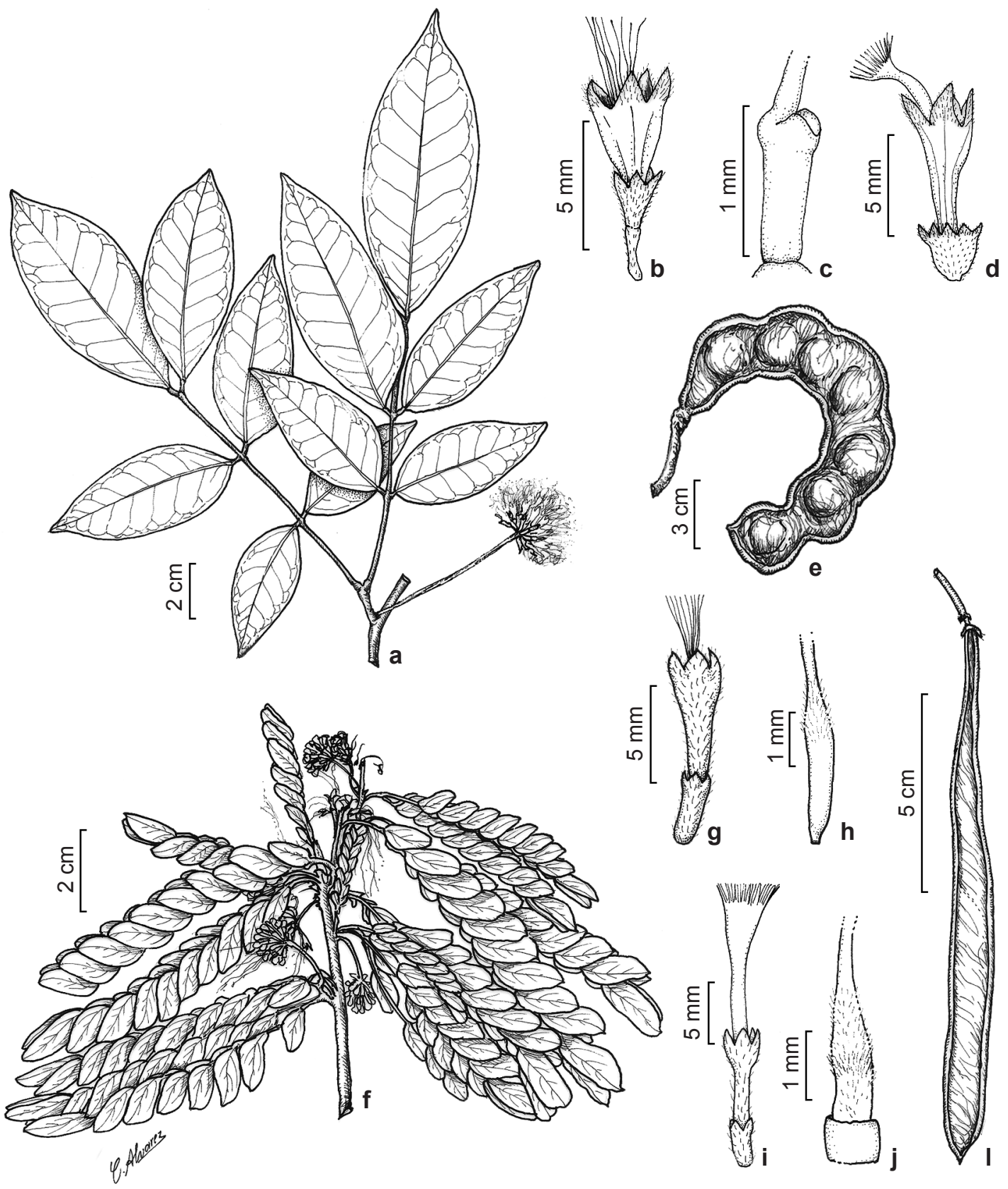

Figura 3 - Abarema mataybifolia: a. ramo com inflorescência; b. flor periférica; c. ovário; d. flor central; e. fruto (a-d M.A. Freitas 1192; e U.N. Maciel 433). Calliandra surinamensis: f. ramo com inflorescência; g. flor periférica; h. ovário da flor periférica; i. flor central; j. disco intraestaminal e ovário da flor central; 1. fruto (f-1 F. Bonadeu 347). Figure 3 - Abarema mataybifolia: a. branch and inflorescence; b. peripheral flower; c. ovary; d. central flower; e. fruit (a-d M.A. Freitas 1192; e U.N. Maciel 433). Calliandra surinamensis: f. branch and inflorescence; g. peripheral flower; h. ovary of the peripheral flower; i. central flower; j. intrastaminal disc and ovary of the central flower; 1. fruit (f-1 F. Bonadeu 348).

$0,75 \mathrm{~mm}$ compr., tomentosos; corola tubular, ca. 8 mm compr., glabra, não estriada, estriada, lobos agudos, ca. $1 \mathrm{~mm}$ compr., pubescentes; estames $1,7 \mathrm{~cm}$ compr., tubo estaminal exserto, filetes ca. $1 \mathrm{~cm}$ acima da corola, disco intraestaminal ausente. Ovário séssil, ca. 1-2 mm compr., glabro. Frutos do tipo legumes, com pedúnculo $5-7 \mathrm{~mm}$ compr., 9-16,2 × 1,8-2,2 ×0,3-0,4 cm, curvados 
ou espiralados, glabros, ápice arredondado ou cuneado, base cuneada; faces coriáceas, convexas, reticuladas; margem 1-2 mm esp. Sementes 7-13, ovóides, 1-1,1 × 0,8-1 cm.

Material examinado: Melgaço, Caxiuanã, próximo a oficina da ECFPn, 3.XII.2003, fl., M.A. Freitas 988 (MG); 27.XI.2004, fl., M.A. Freitas 1192 (MG); próximo à base física, 23.IX.1994, fl., D.C. Costa et al. 41 (MG). Portel, Caxiuanã, grade do PPBio, 24.IV.2009, fr., F. Bonadeu et al. 243 (MG).

Material adicional: BRASIL. PARÁ: Paragominas, Itinga do Pará, fazenda Caboré, 4.XII.1979, fr., U.N. Maciel et al. 433 (MG).

No Brasil ocorre do nordeste do Pará até o oeste do Amazonas (Barneby 1998). Na área de estudo foi coletada em floresta ombrófila densa nos municípios de Melgaço e Portel, sendo registrada pela primeira vez para Portel. No presente estudo a espécie foi coletada com flores no mês de setembro, novembro e dezembro e com frutos em abril, em floresta ombrófila densa nos municípios de Melgaço e Portel.

Abarema mataybifolia caracteriza-se por seus foliólulos elípticos, com margem não ciliada, ápice atenuado, bractéolas espatuladas e tomentosas, flor periférica pedicelada (pedicelo ca. $2 \mathrm{~mm}$ compr.), com cálice campanulado, pubescente, não estriado, lobos obtusos e corola tubular, glabra, estriada. Segundo Barneby \& Grimes (1996), A. mataybifolia apresenta dimorfismo nas bractéolas, sendo as proximais triangulares ou lanceoladas e as apicais elípticas, elípticas-espatuladas ou espatuladas. Em Caxiuanã não foi observado esse dimorfismo entre as bractéolas, sendo encontradas apenas bractéolas espatuladas.

4. Calliandra surinamensis Benth., London J. Bot. 3: 105.1844.

Fig. 3f-1

Arbusto 3-5 m alt. Ramos pubescentes a glabros. Estípulas 0,2-1 cm compr., lanceoladas, pubescentes a pilosas, estriadas. Folhas com 1 par de pina; pecíolo cilíndrico, não canaliculado, 0,2-1,3 cm compr., pubescente; raque foliar ausente; nectários extraflorais ausentes no pecíolo e entre folíolos e foliólulos; foliólulos 7-13 pares, parafilídeo ausente, $0,5-2,5 \times 0,1-1,1 \mathrm{~cm}$, rômbicos ou rômbico-lanceolados, membranáceos, glabros em ambas as faces, com nervura principal pilosa na face adaxial, margem ciliada, ápice arredondado ou acuminado, base assimétrica. Inflorescências capituliformes; pedúnculo 1-1,6 cm compr., pubescente; raque $2-3 \mathrm{~mm}$ compr.; bractéolas 1-2 mm compr., deltóides, pubescentes.
Flores com dimorfismo, sésseis. Flor periférica com cálice tubular, ca. $3 \mathrm{~mm}$ compr., pubescente, estriado, lobos cuneados, ca. 0,75 mm compr., pubescentes; corola tubular, 7-9 mm compr., pubescente, não estriada, lobos agudos, ca. $2 \mathrm{~mm}$ compr., pubescentes; estames 3-4,7 cm compr.; tubo estaminal incluso, filetes $2-3,8 \mathrm{~cm}$ compr. acima da corola, disco intraestaminal ausente; ovário séssil, ca. $2 \mathrm{~mm}$ compr., pubescente apenas no ápice. Flor central com cálice tubular, 3-4 mm compr., pubescente, estriado, lobos cuneados ou agudos, ca. $1 \mathrm{~mm}$ compr., pubescentes; corola tubular, 0,9-1 cm compr., pubescente, não estriada, lobos agudos, ca. 2 mm compr., pubescentes; estames ca. 4,6 cm compr., tubo estaminal exserto, filetes ca. 3,5 cm compr. acima da corola, disco intraestaminal presente; ovário estipitado, ca. 2 mm compr., pubescente. Frutos do tipo legumes, sésseis, 6,3-13,4 × 0,7-1,2 × 0,2-0,4 cm, retos, pilosos, ápice e base agudos; faces lenhosas, retas, com nervuras reticuladas proeminentes; margem 2-3 mm esp. Sementes 3-7, elipsóides, 0,8-1,1 $\times 0,9-1 \mathrm{~cm}$.

Material examinado: Melgaço, Estação Científica Ferreira Penna, 12.XII.1999, fl. e fr., A.S.L. da Silva 3692 (MG); 3.XI.2003, fl. e fr., A.S.L. da Silva 4375 (MG); 27.IV.2009, fl. e fr., F. Bonadeu et al. 347 (MG).

Segundo Souza (2010), a espécie só ocorre nos estados do Pará, Amazonas e Acre. No entanto, Barneby (1998) cita a espécie para os estados de Rondônia, Roraima e Maranhão. No litoral paraense é comum em florestas de restinga (Sousa et al. 2009). No presente estudo foi coletada em área antropizada no município de Melgaço e é um novo registro para a Flona de Caxiuanã e floresce e frutifica nos meses de abril, novembro e dezembro.

Calliandra surinamensis caracteriza-se por seu hábito arbustivo, foliólulos rômbicos ou rômbico-lanceolados, glabros em ambas as faces (exceto na nervura principal), margem ciliada, ápice arredondado ou acuminado, bractéolas deltóides, pubescentes, flor periférica séssil, cálice tubular, estriado, lobos cuneados, corola pubescente, não estriada, presença na flor central de disco intraestaminal e ovário estipitado. Souza et al. (2009) descreveram tanto a flor periférica quanto a central com ovário glabro. Nos espécimes aqui estudados, ambas as flores apresentaram ovário pubescente, sendo a flor periférica coberta por indumento apenas no ápice do ovário. Segundo Barneby (1998), a presença de pubescência na flor central de $C$. surinamensis muitas vezes é um indicativo de que o ovário foi fecundado. 
5. Enterolobium schomburgkii (Benth.) Benth., Trans. Linn. Soc. London 30(3): 599. 1875.

Fig. 4a-i

Árvore 10-30 m alt. Ramos tomentosos a glabros. Estípulas 0,7-1,5 cm compr., lanceoladas, tomentosas. Folhas com 14-21 pares de pinas; pecíolo cilíndrico, não canaliculado, 1,2-2,4 cm compr., tomentoso a pubescente; raque foliar cilíndrica, não canaliculada, 5,5-19 cm compr., tomentosa; nectários extraflorais presentes no pecíolo, ca. $5 \mathrm{~mm}$ diâm., pateliformes, sésseis e entre os últimos pares de folíolos, ca. $1 \mathrm{~mm}$ diâm., pateliformes, sésseis, ausentes entre os foliólulos; foliólulos 20-50 pares, parafilídeo ausente, 1,5-6 $\times 1 \mathrm{~mm}$, oblongos, cartáceos, glabros em ambas as faces, margem ciliada, ápice arredondado, base assimétrica. Inflorescências capituliformes; pedúnculo $0,5-2,1 \mathrm{~cm}$ compr., tomentoso; raque floral ca. $2 \mathrm{~mm}$ compr.; bractéolas ca. $2 \mathrm{~mm}$ compr., espatuladas, tomentosas. Flores com dimorfismo. Flor periférica com pedicelo ca. $1 \mathrm{~mm}$ compr., cálice tubular, ca. $2 \mathrm{~mm}$ compr., tomentoso, não estriado, lobos agudos, ca. $1 \mathrm{~mm}$ compr.; corola tubular, ca. $4 \mathrm{~mm}$ compr., tomentosa, não estriada, lobos regulares, agudos, ca. $1 \mathrm{~mm}$ compr; estames ca. $8 \mathrm{~mm}$ compr., tubo estaminal incluso, filetes ca. $4 \mathrm{~mm}$ acima da corola, disco intraestaminal ausente; ovário séssil, ca. $1 \mathrm{~mm}$ compr., tomentoso. Flor central séssil, cálice campanulado, ca. $3 \mathrm{~mm}$ compr., tomentoso, não estriado, lobos agudos, ca. $1 \mathrm{~mm}$ compr.; corola tubular, 5-6 mm compr., tomentosa, não estriada, lobos agudos, ca. $1 \mathrm{~mm}$ compr.; estames ca. $1 \mathrm{~cm}$ compr., tubo estaminal exserto, filetes ca. $5 \mathrm{~mm}$ acima da corola, disco intraestaminal presente, ovário séssil, ca. $1 \mathrm{~mm}$ compr., tomentoso. Frutos do tipo legumes nucóides, com pedúnculo $0,5-2,1 \mathrm{~cm}$ compr., 13,5$16,7 \times 4,6-5,7 \times 0,6-0,8 \mathrm{~cm}$, curvados, levemente pubescentes, ápice arredondado, base truncada; faces lenhosas, retas, reticuladas; margem 1-5 mm esp. Sementes 22-30, ovóides ou obovóides, 1-1,2 $\times 0,4-0,6 \mathrm{~cm}$.

Material examinado: Melgaço, Estação Científica Ferreira Penna, base física, 27.IV.2009, fr., F. Bonadeu et al. 244 (MG).

Material adicional: BRASIL. PARÁ: Almeirim, Reserva genética do Jari, 18.VIII.1986, fl., J.M. Pires \& N.T. Silva 1355 (MG).

No Brasil a ocorrência da espécie é registrada nos estados de Roraima, Pará, Amazonas, Acre, Rondônia, Maranhão, Piauí e Mato Grosso (Mesquita 1990) e ainda para o Amapá (Morim 2010a). Sua distribuição está circunscrita aos domínios Amazônico e Cerrado. Na área de estudo a espécie foi coletada em área antropizada, com resquício de floresta ombrófila e foi coletado com frutos no mês de abril.

Enterolobium schomburgkii é reconhecida por apresentar foliólulos oblongos diminutos (1,5-6 mm compr.) e em grande número (de 14-21 pares), presença de nectários extraflorais nos pecíolos, frutos do tipo legumes nucóides, curvados, com faces lenhosas e com muitas sementes (22-30), ovóides ou obovóides. Ramos \& Ferraz (2008) classificaram o fruto de $E$. schomburgkii como legume nucóide, plano, com ápice e base arredondados e com 4-22 sementes por fruto. Esses resultados concordam com os registrados no presente estudo, com exceção da base e do número de sementes (truncada e 22-30 sementes, respectivamente).

6. Hydrochorea corymbosa (Rich.) Barneby \& J. W. Grimes, Mem. New York Bot. Gard. 74(1): 27. 1996.

Fig. 5a-f

Árvore 4-8 m alt. Ramos glabros. Estípulas não visualizadas. Folhas com 2-3 pares de pinas; pecíolo cilíndrico, não canaliculado, 1,4-2,4 cm compr., pubescente; raque foliar cilíndrica, não canaliculada, 0,8-2 cm compr., pubescente; nectários extraflorais ausentes no pecíolo e entre os folíolos, presentes entre os foliólulos, 0,7-1 mm diâm., cupuliformes, sésseis; foliólulos 4-7 pares, parafilídeo ausente, 1-2,2 × 0,6-1,4 cm, rômbico-lanceolados ou rômbico-ovais, coriáceos, face adaxial glabra, face abaxial pubescente, ferrugínea, margem ciliada, ápice obtuso, base levemente assimétrica. Inflorescências capituliformes; pedúnculo 4,5-6,3 cm compr., pubescente a glabro; raque floral 5-8 $\mathrm{mm}$ compr.; bractéolas $0,7-1 \mathrm{~mm}$ compr., lineares nas flores periféricas e linear-elípticas nas flores centrais, pubescentes. Flores com dimorfismo. Flor periférica com pedicelo 5-8 mm compr., cálice campanulado, 1-1,7 mm compr., pubescente, não estriado, lobos agudos, ca. 0,2 mm compr.; corola infudibuliforme, ca. $5 \mathrm{~mm}$ compr., glabrescente, estriada, lobos agudos, 1-2 mm compr., pubescentes; estames ca. $1,1 \mathrm{~cm}$ compr., tubo estaminal incluso, filetes ca. $6 \mathrm{~mm}$ acima da corola, disco intraestaminal ausente; ovário estipitado, ca. 1,5 mm compr., tomentoso no ápice. Flor central séssil, cálice tubular, ca. $3 \mathrm{~mm}$ compr., pubescente, não estriado, lobos agudos, ca. $1 \mathrm{~mm}$ compr.; corola infundibuliforme, ca. $7 \mathrm{~mm}$ compr., glabrescente, estriada, lobos agudos, ca. $2 \mathrm{~mm}$ compr., pubescentes; estames ca. 1,6 mm compr., tubo 

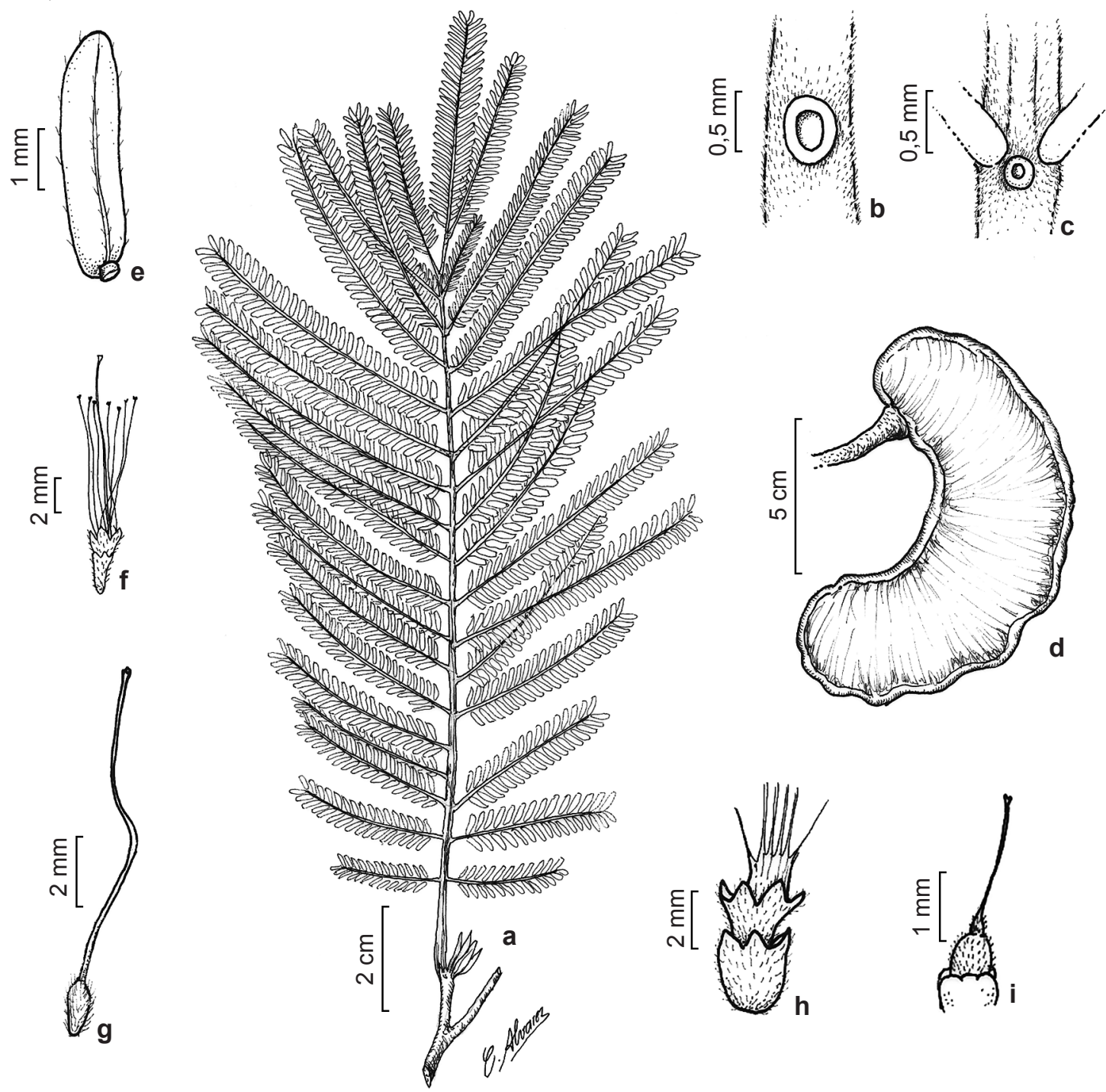

Figura 4 - Enterolobium schomburgkii: a. ramo; b. nectário foliar do pecíolo; c. nectário foliar entre os folíolos; d. fruto; e. foliólulo; f. flor periférica; g. ovário da flor periférica; $h$. flor central; i. disco intraestaminal e ovário da flor central (a-e F. Bonadeu et al. 244 ; f-i J.M. Pires \& N.T. Silva 1355).

Figure 4. Enterolobium schomburgkii: a. branch; b. petiolarnectary; c. petiolar nectary between the leaflets; d. fruit; e. leaflet; f. peripheral flower; g. ovary of the peripheral flower; h. central flower; i. intrastaminal disc and ovary of the central flower (a-e F. Bonadeu 244 et al.; f-iJ.M. Pires \& N.T. Silva 1355).

estaminal inclusos, filetes ca. $3 \mathrm{~mm}$ acima da corola, disco intraestaminal ausente; ovário séssil, ca. $1,2 \mathrm{~mm}$ compr., tomentoso no ápice. Frutos do tipo lomentos drupáceos, com pedúnculo 6-7 mm compr., 4,8-5,6× $1,3-1,7 \times 0,1 \mathrm{~cm}$, retos, incanos, ápice apiculado, base atenuada; faces coriáceas, retas, levemente constritas entre as sementes, reticuladas; margem ca. $0,7 \mathrm{~mm}$ esp. Sementes não vistas.

Material examinado: Melgaço, Caxiuanã, margem do Rio Caxiuanã, 14.X.1991, fr., A.S.L. da Silva \& M.C. Silva 2408 (MG).
Material adicional: BRASIL. PARÁ: Ilha de Mosqueiro, 16.VI.1975, fl., R.R. Santos \& G.S. Pinheiro (IAN 148515).

Barneby \& Grimes (1996) afirma que a espécie é dispersa em quase toda a bacia Amazônica, dado este não confirmado por Morim (2010b), sendo registrada apenas para os estados do Acre, Rondônia, Maranhão Mato Grosso, Goiás e Mato Grosso do Sul. De acordo com Flores \& Rodrigues (2010), ocorre também em áreas de savanas no estado de Roraima. Em Melgaço foi coletada em floresta ombrófila densa, sendo um 

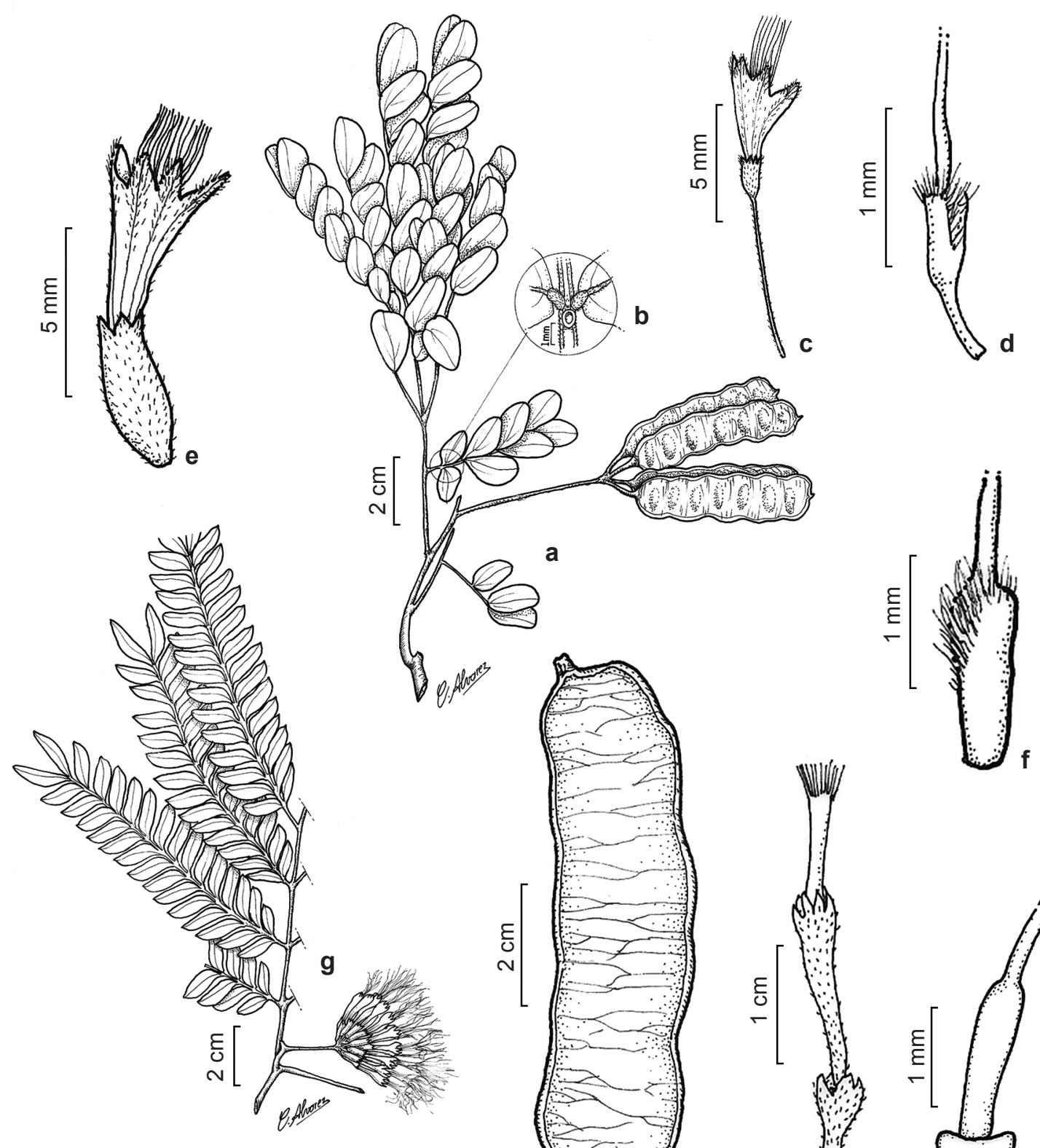

Figura 5 - Hydrochorea corymbosa: a. ramo com frutos; b. nectário foliar; c. flor periférica; d. ovário da flor periférica; e. flor central; f. ovário da flor central (a-b A.S.L. da Silva \& M.C. da Silva 2408; c-f R.R. Santos \& G.S. Pinheiro IAN 148515). Macrosamanea pubiramea var. pubiramea: g. ramo com inflorescência; h. fruto; i. flor; j. disco intraestaminal e ovário (g, i-j M.M. Félix-da-Silva 302; h M.M. Félix-da-Silva 364).

Figure 5-Hydrochorea corymbosa: a. branch and fruit; b. foliar nectary; c. peripheral flower; d. ovary of the peripheral flower; e. central flower; f. ovary of the central flower (a-b A.S.L. da Silva \& M.C. da Silva 2408; c-f R.R. Santos \& G.S. Pinheiro IAN 148515). Macrosamanea pubiramea var. pubiramea: g. branch and inflorescence; h. fruit; i. flower; j. intrastaminal disc and ovary (g, i-j M.M. Félix-da-Silva 302; h M.M. Félix-da-Silva 364).

novo registro para a Flona de Caxiuanã, coletada com frutos no mês de outubro.

Hydrochorea corymbosa apresenta como características diagnósticas hábito arbóreo, foliólulos com 4-7 pares, rômbico-lanceolados ou rômbico-ovais, coriáceos, com face abaxial ferrugínea, ápice obtuso, flores com dimorfismo, flor periférica com pedicelo longo em relação às 
demais espécies aqui estudadas, alcançando 5-8 $\mathrm{mm}$ compr. e frutos do tipo lamentos drupáceos, com ápice apiculado, base atenuada. Segundo Barneby \& Grimes (1996) a flor central de $H$. corymbosa apresenta-se séssil ou pedicelada (1 mm compr.) e sua corola campanulada ou cilindrocampanulado. Para a área de estudo o espécime apresentou flor central séssil e com cálice tubular.

7. Macrosamanea pubiramea (Steud.) Barneby \& J. W. Grimes var. pubiramea, Mem. New York Bot. Gard.74(1): 194. 1996.

Fig. $5 \mathrm{~g}-\mathrm{j}$

Arbusto ca. 1,5 m alt. Ramos pubescentes a glabros. Estípulas 2-5 mm comp., lanceoladas, tomentosas a pubescentes. Folhas com 3-9 pares de pinas; pecíolo cilíndrico, não canaliculado, $0,7-2,5 \mathrm{~cm}$ compr., tomentoso a pubescente; raque foliar cilíndrica, canaliculada, 6,8-14 cm compr., tomentosa; nectários extraflorais presentes no pecíolo, ca. $2 \mathrm{~mm}$ diâm. e entre os folíolos, ca. $1 \mathrm{~mm}$ diâm., pateliformes, ausentes entre os foliólulos; foliólulos 9-20 pares, parafilídeo ausente, $0,6-2,8 \times 0,2-0,7 \mathrm{~cm}$, rômbico-lanceolados, membranáceos, face adaxial pubescente ou glabra, face abaxial glabra, margem ciliada, ápice cuneado, agudo ou arredondado, base assimétrica. Inflorescências espiciformes; pedúnculo 1,7-5,4 cm compr., pubescente; raque floral ca. $5 \mathrm{~mm}$ compr.; bractéolas não visualizadas. Flores sem dimorfismo, sésseis; cálice infundibuliforme, 7-8 mm compr., pubescente, não estriado, lobos agudos, ca. $2 \mathrm{~mm}$ compr.; corola tubular, 1,5-2,2 cm compr., pubescente, estriada, lobos agudos, 2-4 mm compr.; estames 4-5,4 cm compr., tubo estaminal exserto, filetes $0,8-1,3 \mathrm{~cm}$ acima do tubo da corola, disco intraestaminal presente; ovário estipitado, 2-3 mm compr., glabro. Frutos do tipo folículos, pedunculados ou sésseis, com pedúnculo 2-3 mm compr., 8,2-11,5 × 1,6-2,6 × 0,1-0,2 cm, retos, glabros, ápice arredondado ou truncado, base cuneada; faces cartáceas, retas, reticuladas; margem ca. $1 \mathrm{~mm}$ esp. Sementes não vistas.

Material examinado: Melgaço, Caxiuanã, próximo igarapé Puraquequara, 15.X.1991, fr., A.S.L. da Silva \& M.C. da Silva 2415A (MG); 29.X.1999, fl., A.S.L. da Silva \& M.C. da Silva 3643 (MG); 15.X.1991, fr., A.S.L. da Silva \& M.C. da Silva 2415B (MG); margem rio Curuá, 16.X.1991, A.S.L. da Silva \& M.C. da Silva 2434 (MG); 3.XI.2003, fr., A.S.L. da Silva \& M.C. da Silva 4376 (MG); 18.V.2002, fl., J. Oliveira et al. 396 (MG); margem igarapé Laranjal, 19.X.1997, fl., A. Lins et al. 709 (MG); 23.VII.2007, fl., M.M. Félix-da-Silva et al. 302 (MG); 11.XI.2007, fr., M.M. Félix-da-Silva et al. 364 (MG).
No Brasil ocorre nos estados do Amapá, Pará, Amazonas e Acre, apresentando distribuição restrita ao domínio Amazônico (Morim 2010c). Ocorre no município de Melgaço em floresta ombrófila densa, é um novo registro para a área de estudo. Coletada com flores nos meses de maio, julho e outubro e frutos de outubro a novembro.

Macrosamanea puberamea var. puberamea caracteriza-se por possui hábito arbustivo, raque foliar canaliculada, foliólulos com 9-20 pares, rômbico-lanceolados, membranáceos, ápice cuneado, agudo ou arredondado, flores sem dimorfismo, nectário extrafloral no pecíolo, corola estriada e frutos do tipo folículos, com ápice arredondado ou truncado, base cuneada, com faces cartáceas. Barneby \& Grimes (1996) descreveram para a variedade, foliólulos lanceolados ou rômbico-oblongos. Entretanto, o espécime aqui estudado possui foliólulos rômbico-lanceolados.

8. Zygia latifolia var. lasiopus (Benth.) Barneby \& J. W. Grimes, Mem. New York Bot. Gard. 74(2): 120. 1997.

Fig. 6a-d

Árvore ou arbusto escandente 3-10 m alt. Ramos pubescentes a glabros. Estípulas 1-2 $\mathrm{mm}$ compr., lanceoladas, pubescentes, estriadas. Folhas com 2 pares de pinas; pecíolo cilíndrico, não canaliculado, $0,2-1 \mathrm{~cm}$ compr., pubescente a glabrescente; raque foliar ausente; nectários extraflorais ausentes no pecíolo e entre os folíolos, presentes entre os foliólulos, ca. $1 \mathrm{~mm}$ diâm., pateliformes; foliólulos 2-3 pares, sendo 1 par formado pelo parafilídeo, 1-7,2 × 0,6-2,7 cm, elípticos ou oval-elípticos, membranáceos, glabros, com nervura principal pubescente, margem não ciliada, ápice acuminado ou levemente mucronado, base cuneada, levemente assimétrica. Inflorescências espiciformes; pedúnculo 2-7 mm compr., pubescente; raque floral ca. $1 \mathrm{~mm}$ compr.; bractéolas ca. $0,2 \mathrm{~mm}$ compr., cimbiformes, pubescentes. Flores sem dimorfismo, sésseis; cálice campanulado, 0,2-1 mm compr., pubescente, estriado, lobos obtusos, ca. 0,2 $\mathrm{mm}$ compr., pubescentes; corola tubular, 4-7 mm compr., glabrescente, não estriada, lobos agudos, 1-2 mm compr.; estames $1,5-2,5 \mathrm{~cm}$ compr., tubo estaminal exserto, filetes $1-1,5 \mathrm{~cm}$ acima do tubo da corola, disco intraestaminal presente; ovário estipitado, ca. $1 \mathrm{~mm}$ compr., tomentoso. Frutos do tipo legumes, sésseis, 3-6 × 1,5-1,8 $\times 0,1 \mathrm{~cm}$, retos ou levemente curvados, pubescentes, ápice arredondado ou cuspidado, base aguda; faces coriáceas, retas ou convexas, reticuladas; margem ca. $1 \mathrm{~mm}$ esp. Sementes não vistas. 


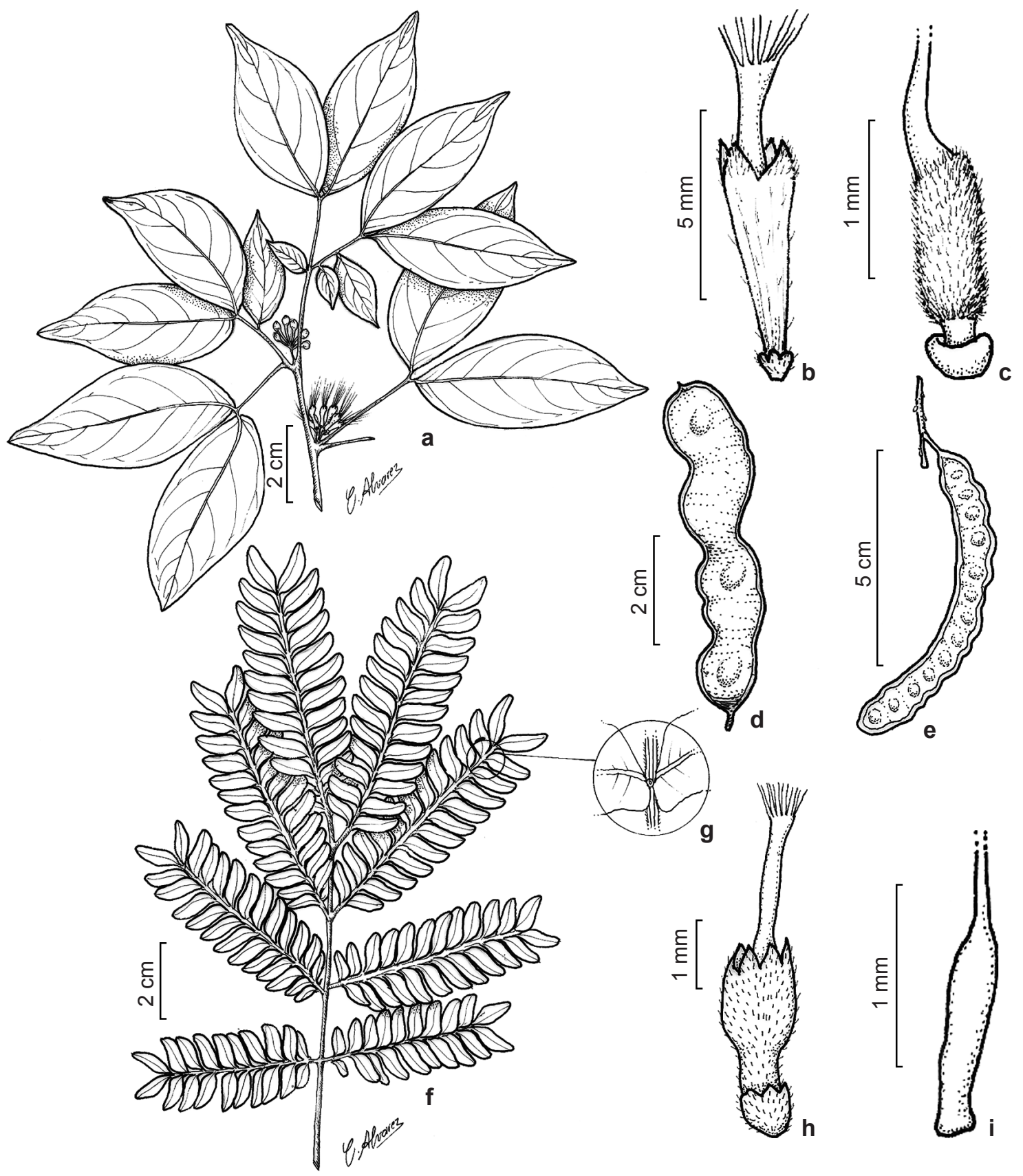

Figura 6-Zygia latifolia var. lasiopus: a. ramo com inflorescência; b. flor; c. disco intraestaminal e ovário; d. fruto (a-c C.A. Cid 1999; d S.S. de Almeida 430). Zygia racemosa: e. fruto; f. folha g. nectário foliar; h. flor; i. ovário (e-g F. Bonadeu 242; h-i M.M. Félix-da-Silva 140).

Figura 6-Zygia latifolia var. lasiopus: a. branch and inflorescence; b. flower; c. intrastaminal disc and ovary; d. fruit (a-c C.A.Cid 1999; d S.S. de Almeida 430). Zygia racemosa: e. fruit; f. leaf; g. foliar nectary; h. flower; i. ovary (e-g F. Bonadeu 242; h-i M.M. Félix-da-Silva 140).

Material examinado: Melgaço, Caxiuanã, margem do Rio Curuá, 2.II.1991, fr., S.S. de Almeida et al. 430 (MG). Material adicional: BRASIL. AMAZONAS: Rio Negro entre Ilha Uabetuba e Ilha da Silva, 14.X.1971, fl., G.T. Prance et al. 15250 (MG). Manaus, Rio Urubu,
13.VIII.1974, fl., G.T. Prance et al. 21648 (MG). São Luiz, Rio Negro, 28.VI.1979, fl., L. Alencar 123 (MG). PARÁ: Oriximiná, rio Paru do Oeste, 4.IX.1980, fl., C.A. Cid et al. 1999 (MG); rio Trombetas, 2.VII.1980, fl., $A$. Cid et al. 1239 (MG). 
No Brasil ocorre nos estados de Roraima, Amapá, Pará, Amazonas, Rondônia e Mato Grosso (Garcia et al. 2010). A espécie foi coletada em floresta aluvial (várzea) e é um novo registro para a área de estudo, na qual foi coletada em fase de frutificação no mês de fevereiro.

Zygia latifolia var. lasiopus é reconhecida por apresentar dois pares de pinas, raque foliar ausente, foliólulos elípticos ou oval-elípticos, de ápice acuminado ou levemente mucronado, presença de bractéolas cimbiformes, flor com cálice estriado e ovário estipitado, tomentoso. Assemelha-se a $Z$. racemosa por apresentarem parafilídeos, estípulas lanceoladas e estriadas e frutos do tipo legume, porém difere-se desta pela ausência de raque foliar e por possuir disco intraestaminal.

9. Zygia racemosa (Ducke) Barneby \& J. W. Grimes, Arch. Jard. Bot. Rio de Janeiro 1: 14. 1915.

Fig. 6e-i

Árvore 7-18,7 m alt. Ramos glabros. Estípulas 5-8 mm comp., lanceoladas, pubescentes, estriadas. Folhas com 4-6 pares de pinas; pecíolo cilíndrico, canaliculado, 0,8-1,9 cm compr., tomentoso; raque foliar cilíndrica, canaliculada, 4,6-11,8 cm compr., tomentosa; nectários extraflorais ausente no pecíolo e entre os folíolos, presentes entre os foliólulos, 0,7-1 mm diâm., pateliformes ou cupuliformes, sésseis, presentes entre o primeiro e os dois últimos pares; foliólulos 5-15 pares, sendo 1 par formado pelo parafilídeo, $0,5-2 \times 0,3-0,6 \mathrm{~cm}$, rômbicolanceolados, membranáceos, glabros, margem não ciliada, ápice mucronado, mucronado-emarginado, base assimétrica. Inflorescências espiciformes; pedúnculo 5-6 $\mathrm{mm}$ compr., tomentoso a pubescente; raque floral ca. $3 \mathrm{~mm}$ compr.; bractéolas ca. $0,25 \mathrm{~mm}$ compr., ovais, tomentosas. Flores sem dimorfismo, sésseis; cálice tubular, ca. $0,25 \mathrm{~mm}$ compr., não estriado, pubescente, lobos agudos ou obtusos, ca. $0,25 \mathrm{~mm}$ compr.; corola infundibuliforme, ca. $2 \mathrm{~mm}$ compr., pubescente, não estriada, lobos agudos, ca. $2 \mathrm{~mm}$ compr.; estames ca. $1 \mathrm{~cm}$ compr., tubo estaminal exsertos, filetes $5-8 \mathrm{~mm}$ acima do tubo da corola, disco intraestaminal ausente; ovário séssil, ca. 1,25 mm compr., glabro. Frutos do tipo legumes com pedúnculo $2-9 \mathrm{~mm}$ compr., $3-11 \times 0,6-1 \times 0,2-0,3 \mathrm{~cm}$, levemente curvados ou curvados, velutinos, ápice arredondado ou cuneado, base aguda, faces lenhosas, convexas; margem ca. 2 mm esp. Sementes 2-13, ovóides, 3-5 × 2-5 mm. Material examinado: Melgaço, Caxiuanã, Estação Científica Ferreira Penna, 1.XII.2003, fr., M.A. Freitas 966 (MG); base física, 3.XI.2003, fr., A.S.L. da Silva 4374 (MG);
5.IV.2009, fr., F. Bonadeu et al. 242 (MG). Portel, Caxiuanã, grade do PPBio, 31.I.2007, fl., M.M. Félix-da-Silva et al. 140 (MG); 17.XI.2007, fl., M.M. Félix-da-Silva 406 (MG).

Amplamente distribuída na Amazônia Brasileira, presente no Amapá, Pará, Amazonas, Rondônia, Maranhão e Mato Grosso, ocorrendo em florestas de terra firme, de solo argiloso (Silva 2008). Segundo Barneby \& Grimes (1997) pode ocorrer em campina. Na área de estudo foi coletada na borda e no interior de floresta ombrófila densa, com flores nos meses de janeiro e outubro e frutos em maio, outubro e novembro.

Zygia racemosa caracteriza-se por apresentar folhas com 4-6 pares de pinas, raque foliar presente, foliólulos rômbico-lanceolados, ápice mucronado ou mucronado-emarginado, bractéolas ovais, tomentosas, flor com cálice não estriado, ovário séssil, tomentoso. Essa espécie apresenta grande importância madeireira, conhecida no Brasil como "angelim-pedra", "angelim-rajado", "ingárana" e "urubuzeiro" (Barneby \& Grimes 1997).

\section{Agradecimentos}

Ao Programa de Pesquisa em BiodiversidadePPBio e à Estação Científica Ferreira PennaECFPn/MEPG, o apoio logístico; a Universidade Federal Rural da Amazônia e ao Museu Paraense Emílio Goeldi a infra-estrutura para a realização de pesquisa; à Coordenação de Aperfeiçoamento de Pessoal de Nível Superior-CAPES, a bolsa de mestrado concedida à autora; J. L. Magalhães e a A. K. Koch, a ajuda nas coletas do material botânico; aos curadores das coleções a disponibilização do material botânico; ao ilustrador botânico C. Álvares, a ajuda na confecção das pranchas.

\section{Referências}

Almeida, S.S.; Lisboa, P.L.B. \& Silva, A.S.L. 1993. Diversidade florística de uma comunidade arbórea na Estação Científica Ferreira Penna, em Caxiuanã (Pará). Boletim Museu Paraense Emílio Goeldi, ser. Bot. 9: 99-120.

Amaral, D.D.; Almeida, S.S. \& Costa, D.C.T. 2009. Contribuição ao manejo florestal de espécies de valor madeireiro e não madeireiro na Floresta Nacional de Caxiuanã. In: Lisboa, P.L.B (ed.). Caxiuanã: Desafios para a conservação de uma Floresta Nacional na Amazônia. Museu Paraense Emílio Goeldi, Belém. Pp. 199-228.

Bonadeu, F. 2010. A tribo Ingeae Bentham (LeguminosaeMimosaoideae) na Floresta Nacional de Caxiuanã, Pará, Brasil. Dissertação de Mestrado. Universidade Federal Rural da Amazônia/Museu Paraense Emílio Goeldi, Belém. 135p. 
Barneby, R.C. \& Grimes, J.W. 1996. Silk tree, guanacaste, monkey's earring: a generic system for the synandrous Mimosoideae of the Americas. part. I. Abarema, Albizia, and allies. Memories of the New York Botanical Garden 74: 292.

Barneby, R.C. \& Grimes, J.W. 1997. Silk tree, guanacaste, monkey's earring. A generic system for the synandrous Mimosoideae of the Americas. part. II. Pithecellobium, Cojoba, and Zygia. Memories of the New York Botanical Garden 74: 161.

Barneby, R.C. 1998. Silk tree, guanacaste, monkey's earring. A generic system for the synandrous Mimosoideae of the Americas. part. III. Calliandra. Memories of the New York Botanical Garden 74: 223.

Barroso, G.M; Morim, M.P.; Peixoto, A.L. \& Ichaso, C.L.F. 1999. Frutos e sementes: morfologia aplicada à sistemática de dicotilêdoneas. UFV, Viçosa. Pp. 168-221.

Brummitt, R.K. \& Powell, C.E. 1992. Authors of plant names. Royal Botanic Gardens, Kew. 732p.

Elias, T.S. 1981. Mimosoideae. In: Polhill, R.M. \& Raven, P.H. (eds.). Advances in legume systematics. Vol. 2, part. 1. Royal Botanic Gardens, Kew. Pp. 143-151.

Flores, A.S. \& Rodrigues, R.S. 2010. Diversidade de Leguminose em uma área de savana do estado de Roraima, Brasil. Acta Botanica Brasilica 24: 175-183.

Fidalgo, O. \& Bononi, V.L.R. 1984. Técnicas de coleta, preservação e herborização do material botânico. Instituto de Botânica (Manual, n. 4), São Paulo. 62p.

Filgueiras, T.S.; Nogueira, P.E.; Brochado, A.L. \& Guala II, G.F. 1994. Caminhamento: um método expedito para levantamentos florísticos qualitativos. Cadernos de Geociências 12: 39-43.

Garcia, F.C. 1998. Relações sistemáticas e fitogeográficas de Inga Miller (Leguminosae-Mimosoideae) nas florestas da costa sul e sudeste do Brasil. Tese de Doutorado. Universidade Estadual Paulista, São Paulo. 248p.

Garcia, F.C.P. 2010. Cojoba Britton \& Rose. In: Forzza, R.C. et al. (eds.). Catálogo de plantas e fungos do Brasil. Vol. 2. Rio de Janeiro. 1023p.

Garcia, F.C.P. \& Fernandes, J.M. 2010. Inga Mill. In: Forzza, R.C. et al. (eds.). Catálogo de plantas e fungos do Brasil. Vol. 2. Rio de Janeiro. Pp. 1042-1046.

Garcia, F.C.P.; Fernandes, J.M. \& Silva, C.R. 2010. Zygia P. Browne. In: Forzza, R.C. et al. (eds.). Catálogo de plantas e fungos do Brasil. Vol. 2. Rio de Janeiro. Pp. 1101-1102.

Gonçalves, E.G. \& Lorenzi, H. 2007. Morfologia vegetal: organografia e dicionário ilustrado de morfologia das plantas vasculares. Instituto Plantarum de Estudos da Flora, São Paulo. 441p.

Grimes, J.W. 1999. Inflorescence morphology, heterochromy, and phylogeny in the Mimosoid tribes
Ingeae and Acacieae (Leguminosae: Mimosoideae). Vol. 65. The Botanical Review (Lancaster). Pp. 317-347.

Holmgren, P.K.; Holmgren, N.H. \& Barnet, L.C. 1990. Index Herbarium. 8 ed. Part. I: The herbaria of the world. New York Botanical Garden, New York. 452p.

Iganci, J.R.V. 2008. Abarema Pittier (Leguminosae, Mimosoideae) no Brasil extra-amazônico. Dissertação de Mestrado. Escola Nacional de Botânica Tropical, Rio de Janeiro. 143p.

Iganci, J.R.V. 2010a. Albizia Durazz. In: Forzza, R.C. et al. (eds.). Catálogo de plantas e fungos do Brasil. Vol. 2. Rio de Janeiro. 994p.

Iganci, J.R.V. 2010b. Chloroleucon (Benth.) Britton \& Rose ex Record. In: Forzza, R.C. et al. (eds.). Catálogo de plantas e fungos do Brasil. Vol. 2. Rio de Janeiro. 1021p.

Iganci, J.R.V. 2010c. Pithecellobium Mart. In: Forzza, R.C. et al. (eds.). Catálogo de plantas e fungos do Brasil. Vol. 2. Rio de Janeiro. 1078p.

Iganci, J.R.V. \& Morim, M.P. 2010. Abarema Pittier. In: Forzza, R.C. et al. (eds.). Catálogo de plantas e fungos do Brasil. Vol. 2. Rio de Janeiro. Pp. 989-991.

Lewis, G.P.; Schire, B.; Mackinder, B.; Lock, M. 2005. Legumes of the world. The Royal Botanical Garden, Kew. 577p.

Lewis, G.P. \& Rico-Arce, M.L. 2005. Tribe Ingeae. In: Lewis, G.P.; Schire, B.; Mackinder, B. \& Lock, M. Legumes of the world. The Royal Botanical Gardens, Kew. 577p.

Lima, H.C. 2010. Cedrelinga Ducke. In: Forzza, R.C. et al. (eds.). Catálogo de plantas e fungos do Brasil. Vol. 2. Rio de Janeiro. 1006p.

Lima, H.C. et al. 2010. Fabaceae. In: Forzza, R.C. et al. (eds.). Catálogo de plantas e fungos do Brasil. Vol. 2. Rio de Janeiro. Pp. 989-1102.

Lisboa, P.L.B.; Silva, A.S.L. \& Almeida, S.S. 1997. Florística e estrutura dos ambientes. In: Lisboa, P.L.B. (ed.). Caxiuanã. Museu Paraense Emílio Goeldi, Belém. Pp. 163-183.

Lisboa, P.L.B. \& Ferraz, M.G. 1999. Estação Científica Ferreira Penna: Ciência \& desenvolvimento sustentável na Amazônia. Museu Paraense Emílio Goeldi, Belém. 151p.

Luckow, M.; White, P.J. \& Bruneau, A. 2000. Relationships among the basal genera of mimosoid legumes. In: Herendeen, P.S. \& Bruneau, A. (eds.). Advances in legume systematics. Vol. 9. Royal Botanic Gardens, Kew. Pp. 165-180.

Luckow, M.; Miller, J.T.; Murphy, D.J. \& Livshultz, T. 2003. A phylogenetic analysis of the Mimosoideae (Leguminosae) based on chloropast DNA sequence data. In: Klitgaard, B.B. \& Bruneau, A. (eds.). Advances in legume systematics. Vol. 10. Royal Botanic Gardens, Kew. Pp. 197-220. 
Mesquita, A.L. 1990. Revisão de Enterolobium Mart. (Leguminosae-Mimosoideae) para a região Neotropical. Dissertação de Mestrado. Universidade Federal Rural de Pernambuco. 222p.

Morim, M.P. 2010a. Enterolobium Mart. In: Forzza, R.C. et al. (eds.). Catálogo de plantas e fungos do Brasil. Vol. 2. Rio de Janeiro. Pp. 1034-1035.

Morim, M.P. 2010b. Hydrochorea Barneby \& J. W. Grimes. In: Forzza, R.C. et al. (eds.). Catálogo de plantas e fungos do Brasil. Vol. 2. Rio de Janeiro. 1040p.

Morim, M.P. 2010c. Macrosamanea Britton \& Rose ex Britton \& Killp. In: Forzza, R.C. et al. (eds.). Catálogo de plantas e fungos do Brasil. Vol. 2. Rio de Janeiro. 1055p.

Morim, M.P. 2010d. Leucochloron Barneby \& J.W. Grimes. In: Forzza, R.C. et al. (eds.). Catálogo de plantas e fungos do Brasil. Vol. 2. Rio de Janeiro. 1047p.

Morim, M.P. 2010e. Samanea Merr. In: Forzza, R.C. et al. (eds.). Catálogo de plantas e fungos do Brasil. Vol. 2. Rio de Janeiro. 1082p.

Pennington, T.D. 1997. The Genus Inga Botany: Royal Botanic Gardens, Kew. 844p.

Programa de Pesquisa em Biodiversidade (PPBio). 2005. Amazônia Oriental. Museu Paraense Emílio Goeldi, Belém. 30p.
Romero, C. 2005. Leguminosae subfamília Mimosoideae, com particular referencia a La Tribu Ingeae. In: Ferero, E. \& Romero, C. (eds.). Estudios em Leguminosas colombianas. Ed. Guadalupe, Bogotá. Pp. 29-38.

Ramos, M.B.P. \& Ferraz, I.D.K. 2008. Estudos morfológicos de frutos, sementes e plântulas de Enterolobium schomburgkii Benth. (Leguminosae-Mimosoideae). Revista Brasileira de Botânica 31: 227-235.

Silva, M.C.R. 2008. Zygia P. Browne (LeguminosaeMimosoideae) na Amazônia Brasileira. Dissertação de Mestrado. Universidade Federal de Viçosa, Minas Gerais. 70p.

Sousa, J.S.; Bastos, M.N.C. \& Rocha, A.E.S. 2009. Mimosoideae (Leguminosae) do litoral paraense. Acta Amazonica 39: 700-812.

Souza, E.R. de. 2010. Calliandra Benth. In: Forzza, R.C. et al. (eds.). Catálogo de plantas e fungos do Brasil. Vol. 2. Rio de Janeiro. Pp. 1002-1004.

Souza, E.R. de \& Lima, H. C. 2010. Zapoteca H.M. Hern. In: Forzza, R.C. et al. (eds.). Catálogo de plantas e fungos do Brasil. Vol. 2. Rio de Janeiro. Pp. 1099-1100.

Tropicos. 2010. Missouri Botanical Garden. Disponível em $<\mathrm{http}$ ://www.tropicos.org > . Acesso em 24 Jan 2010.

Veloso, H.P.; Rangel Filho, A.L.R. \& Lima, J.C.A. 1991. Classificação da vegetação brasileira, adaptada a um sistema universal. IBGE, Rio de Janeiro. 124p.

Lista de Exsicatas

Alencar, L. 123 (9). Almeida, S.S. 403 (1); 430 (9). Bonadeu, F. 242 (10); 243 (3); 244 (6); 347 (4). Cid, C.A. 1239, 1999 (9). Costa, D.C. 41 (3). Daly, D.C. D766 (3). Farria, S.M. de 1042 (1). Félix-da-Silva, M.M. 140 (10); 302, 364 (8); 406 (10). Freitas, M.A. 966 (10); 988, 1192 (3). Lins, A. 709 (8). Maciel, U.N. 433 (3). Oliveira, J. 396 (8). Pires, J.M. 1355 (6). Prance, G.T. 2220 (1); 15250 , 21648 (9). Santos, R.R. s/n IAN 148515 (7). Secco, R.S. 1080 (3). Silva, A.S.L. da 2408 (7); 2414 (2); 2415A, 2415 B, 2434 (8); 3692 (4); 4374(10); 4375 (4); 4376 (8). Silva, M.G. 2743 (3). Silva, N.T. 5508 (3). 